Original Article

\title{
Electrophysiological and clinical evaluation of the effects of transcutaneous electrical nerve stimulation on the spasticity in the hemiplegic stroke patients
}

\author{
Ahmet Karakoyun MD ${ }^{1)}$, İsmail Boyraz, $\left.\mathrm{MD}^{2}\right)^{*}$, Ramazan Gunduz, $\mathrm{MD}^{3)}$, \\ Ayșe Karamercan MD ${ }^{4)}$, Nese Ozgirgin MD ${ }^{5)}$ \\ 1) Department of Physical Therapy and Rehabilitation, Aksaray State Hospital, Turkey \\ 2) Department of Physical Therapy and Rehabilitation, School of Medicine, Abant Izzet Baysal \\ University: Karacasu, Bolu, Turkey \\ 3) Department of Physical Therapy and Rehabilitation, School of Medicine, Karabuk University, \\ Turkey \\ 4) Ankara Special Physical Therapy Center, Turkey \\ 5) Ankara Physical Therapy and Rehabilitation Training and Research Hospital, Turkey
}

\begin{abstract}
Purpose] To investigate whether transcutaneous electrical nerve stimulation (TENS) mitigates the spasticity of hemiplegic stroke patients, as assessed by electrophysiological variables, and the effects, if any, on the clinical appearance of spasticity. [Subjects and Methods] Twenty-seven subjects who had acute hemiplegia and 24 healthy people as the control group, were enrolled in this study. Some of the acute cerebrovascular disease patients could walk. Subjects who did not have spasticity, who were taking antispasticity medicine, or had a previous episode of cerebrovascular disease were excluded. The walking speed of the patients was recorded before and after TENS. EMG examinations were performed on the healthy controls and in the affected side of the patients. A 30-minute single session of TENS was applied to lower extremity. At 10 minutes after TENS, the EMG examinations were repeated. [Results] A statistically significant decrease in the spasticity variables, and increased walking speed were found post-TENS. The lower $\mathrm{M}$ amplitude and higher $\mathrm{H}$ reflex amplitude, H/M maximum amplitude ratio, $\mathrm{H}$ slope, and $\mathrm{H}$ slope/M slope ratio on the spastic side were found to be statistically significant. [Conclusion] TENS application for hemiplegic patients with spastic lower extremities due to cerebrovascular disease resulted in marked improvement in clinical scales of spasticity and significant changes in the electrophysiological variables.

Key words: Hemiplegia, Spasticity, Transcutaneous electric nerve stimulation
\end{abstract}

(This article was submitted Jul. 2, 2015, and was accepted Aug. 5, 2015)

\section{INTRODUCTION}

Cerebrovascular diseases (CVDs) are associated with balance disturbances, dependency in performing daily living activities, and limited ambulation. As life expectancy increases, CVDs are becoming more prevalent ${ }^{1)}$. Spasticity is a speed-dependent resistance to the passive motion of muscles and tendons, developing secondary to enhanced stretch reflexes in patients with upper motor neuron lesions. Spasticity is a major problem in rehabilitation programs, and it hampers patient progress and may trigger severe complications $^{2,3)}$. Quantitative assessment of spasticity is critical when gauging responses to medical treatment and physical

*Corresponding author. Ismail Boyraz (E-mail: boyraz@ yahoo.com)

(C2015 The Society of Physical Therapy Science. Published by IPEC Inc. This is an open-access article distributed under the terms of the Creative Commons Attribution Non-Commercial No Derivatives (by-ncnd) License $<$ http://creativecommons.org/licenses/by-nc-nd/3.0/> . therapy, and when making a prognosis. At present, rather limited clinical scoring systems of spasticity, and biomechanical and electrophysiological data, are used. Electroneuromyographic evaluation of the spinal reflex organization allows detailed follow-up of physiological changes. One of the most common electrophysiological assessment modalities is the $\mathrm{H}$ reflex. This measure, and also the $\mathrm{F}$ reflex, assessed using various techniques, are employed to quantitate and explore spasticity ${ }^{4}$.

Transcutaneous electrical nerve stimulation (TENS) is a rehabilitative form of physical therapy used to treat pain. Various types of nerve fiber are stimulated at different frequencies, wavelengths, and amplitudes. TENS of the A-beta fibers is used to treat spasticity ${ }^{5-7}$. TENS delays the H reflex through the 1a fibers, which mediate presynaptic inhibition ${ }^{8)}$.

In the present study, we evaluated the utility of TENS for patients with spasticity due to CVD, who were undergoing rehabilitation, was evaluated using clinical scoring systems and electrophysiological assessment. This study also aimed to explore whether TENS affects spasticity electrophysiologically, and the extent of the effects on clinical features. 


\section{SUBJECTS AND METHODS}

Patients hospitalized in Ankara Physical Therapy and Rehabilitation Training and Research Hospital, who were participating in a rehabilitation program for hemiplegia with spasticity in the lower extremity, were recruited. The control group consisted of healthy individuals. This study is a clinical trial including a control group. The local ethics committee approved this study. Informed consent was obtained from all of the patients before treatment.

Patients who had received any treatment for spasticity, who lacked spasticity, who had a history of any systemic disease that might cause peripheral neuropathy, or symptoms of radiculopathy in the lower extremities, who had suffered strokes less than 30 days prior, who had a prior history of cerebrovascular disease, who had upper motor neuron damage on the non-hemiplegic side, who could not co-operate, or who were obese, were excluded. Aphasic and geriatric patients were also excluded; because their co-operation was lacking.

Patients with spasticity of at least Ashworth grade 1 in the lower extremities were included. The active motor power and spasticity of all patients were evaluated using the Brunnstrom stage and the Ashworth scale, respectively. Reflex, and superficial and deep sensorial examinations were performed. The time taken to walk $10 \mathrm{~m}$ by patients who could walk was measured before and after TENS.

After a clinical evaluation, EMG examinations were initially performed on healthy controls and, later, on the affected sides of patients. All electrophysiological work was performed in a calm, intermediately lit room with patients in the supine position. Their feet extended from the examination bed, commencing at the ankle joints, each of which was in the $90^{\circ}$ neutral position; the knee joint was at $180^{\circ}$ of extension. All patients were asked to relax their muscles as much as possible during the electrophysiological study. The $\mathrm{H}$ reflexes and $\mathrm{M}$ responses of the gastrocnemius-soleus muscle were electrophysiologically recorded on both the healthy and hemiplegic sides. Subsequently, a single $30 \mathrm{~min}$ session of TENS was applied to the hemiplegic lower extremity. Ten minutes later, the $\mathrm{H}$ reflexes and $\mathrm{M}$ responses were re-assessed and compared with the pre-TENS data.

A Nihon Kohden Neuropack $\mu$ four-channel EMG platform was used for measurements in the single-channel mode. Superficial monopolar disc electrodes were applied. The active electrode was placed on the gastrocnemius-soleus muscle, in a slightly medial position, $14 \mathrm{~cm}$ proximal to the junction of the Achilles tendon and the heel. The reference electrode was placed at the junction of the tendon and the heel, and a Velcro ground electrode was placed between the active electrode and the stimulator. The latter electrode was placed on the fossae popliteal, to stimulate the tibial nerve, and the cathode was placed across the active electrode. The duration of the rectangular stimulus was $1 \mathrm{~ms}$. The stimulus intensity was increased in steps of $2 \mathrm{~mA}$, commencing at zero, and the combined action potentials of the soleus muscle were recorded. The mean of 50 different trajectories was recorded. The peak-to-peak amplitudes and latencies of the $\mathrm{H}$ and $\mathrm{M}$ responses were measured. The latencies were assessed at the point of separation of each response from the baseline. The sensitivity, low frequency filter, and high frequency filter were $2 \mathrm{mV} / \mathrm{dv}, 200 \mathrm{~Hz}$, and $3 \mathrm{kHz}$, respectively. The duration of the analysis was $200 \mathrm{~ms}$. Stimuli were created randomly, and delivered to the popliteal fossa with the posterior tibial nerve lying proximal to the cathode. A rectangular flow $1 \mathrm{~ms}$ in duration, delivered every $2 \mathrm{~s}$, served as the stimulus. The sweep speed and sensitivity were $10 \mathrm{~ms}$ and $2 \mathrm{mV} / \mathrm{dv}$, respectively. First, the maximal amplitude $\mathrm{M}$ response was recorded. Subsequently, the largest $\mathrm{H}$ wave was determined by varying the strength of the stimulus with the location of the stimulator unchanged.

After all electrophysiological work was completed, and all wave amplitudes calculated, the $\mathrm{H} / \mathrm{M}$ maximum amplitude ratio was calculated for each patient by dividing the maximal amplitude of the $\mathrm{H}$ reflex by that of the $\mathrm{M}$ responses from both the healthy and affected sides. In addition, to evaluate alpha motor neuron excitability and the extent of spasticity, the slopes of the rising sides of the $\mathrm{H}$ and $\mathrm{M}$ amplitude-stimulus severity slopes were calculated using Excel and the $\mathrm{H}$ slope, $\mathrm{M}$ slope, and $\mathrm{H}$ slope/M slope values were obtained.

TENS was performed in the supine position with the feet hanging in a neutral manner. Electrodes were placed bilaterally on the tibialis nerve, between the tendon of the muscle and the medial malleolus; thus the gastrocnemius muscle was included. The recording electrodes used in the electrophysiological study were not removed.

A Systems 200E TENS platform was used. This equipment has two output channels the flow intensity in each channel can be adjusted independently. The frequency was $50 \mathrm{~Hz}$ and the pulse width was $100 \mathrm{~ms}$ in normal stimulation. The current intensity was not allowed to exceed a mean of $50 \mathrm{~mA}$ and no contractions were noted.

Twenty-four healthy individuals formed the control group. Their age, gender, and height were recorded. Electrophysiological data were collected before and after TENS, the same as for the patient group. Controls were positioned the same as patients, and TENS was applied for $30 \mathrm{~min}$. Electrophysiological data were gathered from only the right lower extremities of the controls and the pre- and post-TENS values were compared.

Statistical analysis was performed using SPSS for Windows (SPSS Inc., Chicago, IL, USA). The $\chi^{2}$, Wilcoxon signed-rank, and Kruskal-Wallis tests, were used, as appropriate, to evaluate the experimental parameters.

\section{RESULTS}

The patient group with hemiplegia secondary to CVD numbered 27 [12 females (44.4\%) and 15 males (55.6\%)]. A total of 24 healthy subjects [ 10 females $(41.7 \%)$ and 14 males $(58.3 \%)]$ served as controls. The mean ages of the patients and controls were $60.93 \pm 12.8$ and $49.88 \pm 6.85$ years, respectively. The mean heights of the patients and controls were $160.85 \pm 8.99$ and $165.38+8.56 \mathrm{~cm}$, respectively. The mean age, but not height or gender, differed significantly between the groups.

Fourteen (51.9\%) and $13(48.1 \%)$ patients respectively had left- and right-side hemiplegia. The mean duration of hemiplegia (the lesional age) was $181 \pm 167$ days. Thrombo- 
Table 1. Change in the spasticity between pre- and post-TENS

\begin{tabular}{llcc}
\hline & Ashworth 1 & Ashworth 2 & Ashworth 3 \\
\hline Pre-TENS & $10(37 \%)$ & $13(48.2 \%)$ & $4(14.8 \%)$ \\
Post-TENS & $14(51.9 \%)$ & $11(40.7 \%)$ & $2(7.4 \%)$ \\
\hline
\end{tabular}

embolic and hemorrhagic stroke were the principal causes of hemiplegia in $21(77.8 \%)$ and $6(22.2 \%)$ patients, respectively.

Deep sensory nerve findings were normal in all of the patients. Superficial sensory nerve examinations revealed hypoesthesia in 10 patients $(37 \%)$, but 17 were normal $(63 \%)$. The deep tendon reflexes (DTRs) on the hemiplegic sides were normal in the upper extremity of one patient $(3.7 \%)$ but hyperactive in $26(96.3 \%)$; the lower extremity on the affected side was hyperactive in all patients. On the healthy sides, the DTRs were normative in both the upper and lower extremities of $26(96.3 \%)$ patients, and hyperactive in one (3.7\%). No significant difference in the mean pre- and postTENS lower-extremity DTRs on the hemiplegic side was found $(\mathrm{p}>0.05)$.

The values of the spasticity parameters before and after TENS differed significantly in the patient group (Table 1 all $\mathrm{p}$ values $<0.05)$.

Fourteen patients were able to walk, either with support or independently, but 13 were not. The 10 -m walk durations were recorded for patients who could walk. After TENS, 11 patients exhibited increased walking speeds and 3 reduced speeds.

When patient hemiplegic and healthy lower extremities were electrophysiologically compared, the mean maxima of the $\mathrm{H}$ reflex, the $\mathrm{H} / \mathrm{M}$ ratio, the $\mathrm{H}$ slope, and $\mathrm{H}$ slope/M slope ratio, were significantly greater on the affected side. In addition, the mean $\mathrm{M}$ response amplitude was significantly different (greater on the healthy side). The differences in the $\mathrm{H} / \mathrm{M}$ maximum and $\mathrm{H}$ slope/M slope ratios were particularly marked (Table 2).

The $\mathrm{H}$ maximum amplitude values were higher on the spastic hemiplegic side than on the healthy side. The H/M ratio, $\mathrm{H}$ slope, and $\mathrm{H}$ slope/M slope ratio were higher on the affected side. However, the mean $\mathrm{M}$ amplitude was higher on the normal than on the hemiplegic side. The mean $\mathrm{H}$ reflex amplitude, the $\mathrm{H} / \mathrm{M}$ amplitude ratio, the $\mathrm{H}$ maximum latency, the $\mathrm{H}$ slope, and the $\mathrm{H} / \mathrm{M}$ slope ratio, differed significantly pre- and post-TENS on the hemiplegic side.

The post-TENS electrophysiological changes in the control group were similar to those in the patient group. The $\mathrm{H}$ maximum amplitude, the $\mathrm{H} / \mathrm{M}$ ratio, the $\mathrm{M}$ maximum amplitude, and the $\mathrm{M}$ slope ratio, decreased, whereas the $\mathrm{H}$ and $\mathrm{M}$ maximum latencies increased, with statistical significance.

The duration of disease was positively associated with the mean $\mathrm{H}$ maximum amplitude, the $\mathrm{H} / \mathrm{M}$ ratio, and the H/M slope ratio; however, no association was statistically significant. The $\mathrm{H}$ maximum latency was lowest in patients with disease durations greater than 100 days.

Higher mean $\mathrm{H}$ maximum amplitudes, $\mathrm{H} / \mathrm{M}$ ratios, and $\mathrm{H}$ slopes evident as spasticity worsened. However, only the mean $\mathrm{H}$ slope differed significantly among the spasticity
Table 2. Electrophysiological variables of the healthy and affected sides of the patients

\begin{tabular}{lcc}
\hline Variable & Healthy side & Affected side \\
\hline H max amp (mv) & $1,669.85 \pm 1559.79$ & $2,899.70 \pm 1,698.69$ \\
H max lat (msec) & $31.21 \pm 2.18$ & $31.08 \pm 2.28$ \\
M max amp (mv) & $8,735.89 \pm 2,820.52$ & $7,439.89 \pm 2,825.16$ \\
M max lat (msec) & $4.90 \pm 0.44$ & $4.93 \pm 0.40$ \\
H/M max amp (mv) & $0.19 \pm 0.16$ & $0.42 \pm 0.22$ \\
H slope & $0.01 \pm 0.009$ & $0.03 \pm 0.22$ \\
M slope & $0.03 \pm 0.006$ & $0.03 \pm 0.006$ \\
H/M slope & $0.4 \pm 0.32$ & $0.91 \pm 0.43$ \\
\hline
\end{tabular}

subgroups, with significant differences being found between subgroups I and III, and II and III, in parallel with worsening of spasticity.

\section{DISCUSSION}

TENS significantly reduced spasticity scores and increased the walking speed. On the spastic side, TENS significantly reduced the $\mathrm{M}$ amplitude and increased the $\mathrm{H}$ reflex amplitude, the $\mathrm{H} / \mathrm{M}$ maximum amplitude ratio, the $\mathrm{H}$ slope, and the $\mathrm{H}$ slope/M slope ratio. Also, the mean patient $\mathrm{H}$ reflex amplitude, the $\mathrm{H} / \mathrm{M}$ ratio, the $\mathrm{H}$ slope, and the $\mathrm{H}$ slope/M slope ratio, decreased significantly, and the $\mathrm{H}$ reflex maximum latency increased, after TENS. In controls, TENS significantly decreased the $\mathrm{H}$ maximum amplitude, the $\mathrm{H} / \mathrm{M}$ ratio, the $\mathrm{M}$ maximum amplitude, and the $\mathrm{M}$ slope ratio, and lengthened the $\mathrm{H}$ and $\mathrm{M}$ maximum latencies. The $\mathrm{H}$ maximum latency was the only variable affected by lesional duration. The mean $\mathrm{H}$ maximum amplitude, the $\mathrm{H} / \mathrm{M}$ ratio, and the mean $\mathrm{H}$ slope increased as spasticity worsened on the Ashworth scale. However, only the mean H slope differed significantly among the subgroups.

Bajd et al. explored changes in the spasticity of patients with medulla spinalis injuries after TENS, and found there were short-term reductions in spasticity ${ }^{9}$. Robinson et al. applied 20 min electrical stimulation to the quadriceps muscles of patients with medulla spinalis injuries and reported a significant decrease in leg spasticity ${ }^{10}$. Cho et al. found that a single session of high-frequency TENS significantly improved the spasticity (for less than 1 day) of chronic stroke patients. In addition, short-term significant improvement in balance was evident. Similarly, TENS reduced the spasticity of stroke patients, and repeat TENS reduced the hyperactive tension reflexes of the plantar flexors, and the passive resistance to plantar flexor movement ${ }^{11)}$. In a study that included acute stroke patients, TENS applied to acupuncture points for 3 weeks decreased plantar flexor spasticity and increased dorsiflexion of the ankle joint. In chronic stroke patients, however, ankle joint dorsoflexion was strengthened by stimulation, and muscle co-contraction was decreased. In addition, electrical stimulation increased brain plasticity. Repeated skin stimulation was advocated, to increase the number of cortical fields represented ${ }^{12)}$. In a study that included chronic stroke patients, addition of TENS to a 20 -session rehabilitation program decreased spasticity by 
$30 \%$ and markedly improved muscle strength ${ }^{13)}$. Park et al. showed that balance, walking, and the functional activity of chronic stroke patients improved after 30 TENS sessions (each $30 \mathrm{~min}$ in duration), and a combination of exercise and TENS increased the activation of pathways associated with proprioception and balance ${ }^{14}$. In the present study, a significant decrease in spasticity and an increase in walking speed were evident after acute hemiplegic the patients in a rehabilitation program received a single session of TENS.

Fisher reported that the $\mathrm{M}$ amplitudes of patients with first-motor neuron diseases decreased, after TENS, compared to the amplitudes of polyneuropathic patients ${ }^{15)}$. Angel and Hoffman, who first showed that the H/M ratio was increased in spastic patients, reported mean ratios of 9.17 and 0.48 in the extremities of control and spastic groups, respectively. The excitability of alpha motor neurons increased when various physiopathological mechanisms were in play; therefore, the responses to stimuli carried by la afferent fibers increased ${ }^{16)}$. Garcia-Mullin and Mayer reported mean $\mathrm{H} / \mathrm{M}$ ratios of 0.33 and 0.46 on the healthy and paretic sides, respectively, of spastic hemiplegic stroke patients in whom the disease duration was longer than 90 days ${ }^{17)}$.

Bakhtiary showed that spasticity was reduced by electrical stimulation, but no significant change in the $\mathrm{H}$ reflex amplitude was evident. Also, the $\mathrm{H} / \mathrm{M}$ maximum ratio did not change, and this was attributed to muscle weakness caused by stimulation ${ }^{18)}$. Gaft et al. noted significant decreases in both spasticity and the $\mathrm{H}$ reflex amplitude after stimulation. In the present study, significant differences were found in the $\mathrm{M}$ response and $\mathrm{H}$ reflex amplitude between the healthy and affected sides of spastic the hemiplegic stroke patients. The mean maximum amplitudes of the $\mathrm{H}$ reflexes of the triceps surae were 1,669 and $2,899 \mathrm{mV}$ on the healthy and paretic sides, respectively, and the difference was significant. The difference in the $\mathrm{H} / \mathrm{M}$ ratio between the healthy and plegic sides was also significant ${ }^{19}$.

Huang et al. reported that the H/M maximum and $\mathrm{H} 2$ / H1 ratios were not adequate for defining the extent of spasticity as assessed by the Ashworth scale. The mean H/M maximum and $\mathrm{H} 2 / \mathrm{H} 1$ values increased in stroke patients, compared to healthy controls, but the $\mathrm{M}$ maximum ratio did not significantly differ between the groups. The $\mathrm{H} 2 / \mathrm{H} 1$ and $\mathrm{M}$ maximum ratios did not significantly correlate with other measures of spasticity. In contrast to other previous studies, Huang et al. concluded that the MAS value correlated with the $\mathrm{H} / \mathrm{M}$ ratio ${ }^{20)}$. In the present study, we noted a decrease in the $\mathrm{M}$ amplitude on the spastic side was observed, whereas the $\mathrm{H}$ reflex amplitude and the $\mathrm{H} / \mathrm{M}$ maximum amplitude ratio, increased.

Higashi et al. found that the change in the H slope/M slope ratio was more significant on the spastic than the healthy side, and no significant difference in the H/M maxima of the two sides was evident. As the H slope/M slope graph is bellshaped, such data are more compatible with the Brunnstrom stage of hemiplegic patients than are other indicators. In conclusion, the $\mathrm{H}$ slope/ $\mathrm{M}$ slope ratio is primarily useful for objectively evaluating the extent of spasticity, and the excitability of the motor neuron pool of the spastic sides of hemiplegic patients ${ }^{21)}$. Funase et al. measured the excitability of the motor neuron pool and compared the H/M ratios, the $\mathrm{H}$ maximum amplitude, and the $\mathrm{H}$ slope/ $\mathrm{M}$ slope ratio, in spastic and normal individuals, and found there were marked differences between the two groups. They concluded, the $\mathrm{H}$ slope/M slope ratio was particularly useful for evaluating motor neuron pool excitability ${ }^{22}$. In the present study, steeper $\mathrm{H}$ slope and greater $\mathrm{H}$ slope/M slope ratio on the spastic (compared to healthy) side of hemiplegic patients prior to TENS were observed.

One study evaluating the electrophysiological components of the $\mathrm{H}$ reflex and $\mathrm{F}$ wave compared the pre- and post-TENS $\mathrm{H}$ reflexes, and $\mathrm{F}$ wave latencies and amplitudes, and reported the reduction in spasticity was associated with electrophysiologically proven decreases in the $\mathrm{H}$ reflex amplitude, the $\mathrm{F}$ wave amplitude, and the $\mathrm{H} / \mathrm{M}$ and $\mathrm{F} / \mathrm{M}$ ra$\operatorname{tios}^{23)}$. In another study, TENS was applied segmentally and heterosegmentally to the median nerve of the wrist, and to the common peroneal nerve (placebo). The $\mathrm{H}$ reflex latencies increased in $75 \%$ of the patients in the experimental groups, but the $\mathrm{H}$ amplitude did not change significantly. These findings suggest that long-term TENS might effectively treat spastic hemiparesis ${ }^{24)}$.

Aydin et al. compared TENS with baclofen, the commonest drug prescribed to treat spasticity in patients with medulla spinalis injuries. Significant improvements in all parameters, except pain, were evident in the TENS group, and they were associated with decreases in the $\mathrm{H}$ amplitude and $\mathrm{H} / \mathrm{M}$ ratio, and the $\mathrm{M}$ response. The electrophysiological and clinical changes did not differ significantly between the TENS and baclofen group ${ }^{25)}$. Tekeoglu et al. also reported that TENS reduced spasticity in stroke patients, and improved their capacity to engage in activities of daily living, concluding that TENS effectively improved motor function ${ }^{26}$.

In the present study, a single session of TENS resulted in significant clinical inhibition of spasticity; however, lower extremity strength did not improve. On the spastic side, TENS significantly decreased the mean $\mathrm{H}$ reflex amplitude, the $\mathrm{H} / \mathrm{M}$ ratio, the $\mathrm{H}$ slope, and the $\mathrm{H}$ slope/M slope ratio; and increased the $\mathrm{H}$ reflex maximum latency. This study had some limitation walking speed was not measured after several TENS applications.

In conclusion, TENS for hemiplegic patients with spastic lower extremities due to CVD markedly improved clinical parameters and significantly changed electrophysiological variables. The results of this study suggest that TENS is effective when used to manage spasticity.

\section{REFERENCES}

1) Adams RD, Victor M: In: Principles of Neurology 4 nd, Newyork: Me Graw Hill, 1989, pp 617-692.

2) Mukherjee A, Chakravarty A: Spasticity mechanisms - for the clinician. Front Neurol, 2010, 1: 149. [Medline] [CrossRef]

3) Sosnoff JJ, Gappmaier E, Frame A, et al.: Influence of spasticity on mobility and balance in persons with multiple sclerosis. J Neurol Phys Ther, 2011, 35: 129-132. [Medline] [CrossRef]

4) Pisano F, Miscio G, Del Conte C, et al.: Quantitative measures of spasticity in post-stroke patients. Clin Neurophysiol, 2000, 111: 1015-1022. [Medline] [CrossRef]

5) Ping Ho Chung B, Kam Kwan Cheng B: Immediate effect of transcutaneous electrical nerve stimulation on spasticity in patients with spinal cord injury. Clin Rehabil, 2010, 24: 202-210. [Medline] [CrossRef]

6) Cho HY, Kim EH, Kim B, et al.: Effects of Repetitive High frequency transcutaneous electrical nerve stimulation (HF-TENS) on spasticity and 
motor function following spinal cord injury in rats. J Phys Ther Sci, 2012 24: 133-137. [CrossRef]

7) Mun BM, Kim TH, Lee JH, et al.: Comparison of gait aspects according to FES stimulation position applied to stroke patients. J Phys Ther Sci, 2014, 26: 563-566. [Medline] [CrossRef]

8) Hiraoka K: Neural mechanisms underlying the effect of transcutaneous electrical nerve stimulation in humans. Electromyogr Clin Neurophysiol, 2002, 42: 359-366. [Medline]

9) Bajd T, Gregoric M, Vodovnik L, et al.: Electrical stimulation in treating spasticity resulting from spinal cord injury. Arch Phys Med Rehabil, 1985, 66: 515-517. [Medline]

10) Robinson CJ, Kett NA, Bolam JM: Spasticity in spinal cord injured patients: 1. Short-term effects of surface electrical stimulation. Arch Phys Med Rehabil, 1988, 69: 598-604. [Medline]

11) Cho HY, In TS, Cho KH, et al.: A single trial of transcutaneous electrical nerve stimulation (TENS) improves spasticity and balance in patients with chronic stroke. Tohoku J Exp Med, 2013, 229: 187-193. [Medline] [CrossRef]

12) Yan T, Hui-Chan CW: Transcutaneous electrical stimulation on acupuncture points improves muscle function in subjects after acute stroke: a randomized controlled trial. J Rehabil Med, 2009, 41: 312-316. [Medline] [CrossRef]

13) Ng SS, Hui-Chan CW: Transcutaneous electrical nerve stimulation combined with task-related training improves lower limb functions in subjects with chronic stroke. Stroke, 2007, 38: 2953-2959. [Medline] [CrossRef]

14) Park J, Seo D, Choi W, et al.: The effects of exercise with TENS on spasticity, balance, and gait in patients with chronic stroke: a randomized controlled trial. Med Sci Monit, 2014, 20: 1890-1896. [Medline] [CrossRef]

15) Fisher MA: F/M ratios in polyneuropathy and spastic hyperreflexia. Muscle Nerve, 1988, 11: 217-222. [Medline] [CrossRef]

16) Angel RW, Hofmann WW: The H Reflex In normal, spastic, and rigid subjects. Arch Neurol, 1963, 9: 591-596. [Medline] [CrossRef]

17) Garcia-Mullin R, Mayer RF: H reflexes in acute and chronic hemiplegia.
Brain, 1972, 95: 559-572. [Medline] [CrossRef]

18) Bakhtiary AH, Fatemy E: Does electrical stimulation reduce spasticity after stroke? A randomized controlled study. Clin Rehabil, 2008, 22: 418425. [Medline] [CrossRef]

19) Gaft PG, Kotlik BA, Slivko EI, et al.: [The weakening of the inhibition of the $\mathrm{H}$-reflex in patients who have had a stroke and its relation to spasticity of the skeletal musculature]. Zh Nevrol Psikhiatr Im S S Korsakova, 1994, 94: 16-17. [Medline]

20) Huang CY, Wang CH, Hwang IS: Characterization of the mechanical and neural components of spastic hypertonia with modified $\mathrm{H}$ reflex. J Electromyogr Kinesiol, 2006, 16: 384-391. [Medline] [CrossRef]

21) Higashi T, Funase K, Kusano K, et al.: Motoneuron pool excitability of hemiplegic patients: assessing recovery stages by using H-reflex and $\mathrm{M}$ response. Arch Phys Med Rehabil, 2001, 82: 1604-1610. [Medline] [CrossRef]

22) Funase K, Higashi T, Yoshimura T, et al.: Evident difference in the excitability of the motoneuron pool between normal subjects and patients with spasticity assessed by a new method using H-reflex and M-response. Neurosci Lett, 1996, 203: 127-130. [Medline] [CrossRef]

23) Joodaki MR, Olyaei GR, Bagheri H: The effects of electrical nerve stimulation of the lower extremity on H-reflex and F-wave parameters. Electromyogr Clin Neurophysiol, 2001, 41: 23-28. [Medline]

24) Hui-Chan WY, Cliristiana, Levin PM: Stretch reflex latencies in spastic hemiparetic subjects are prolonged after transcutaneous electrical nerve stimulation. Can I Neurol Sci, 1993, 20: 97-106.

25) Aydın G, Tomruk S, Keleș I, et al.: Transcutaneous electrical nerve stimulation versus baclofen in spasticity: clinical and electrophysiologic comparison. Am J Phys Med Rehabil, 2005, 84: 584-592. [Medline] [CrossRef]

26) Tekeoğlu Y, Adak B, Göksoy T: Effect of transcutaneous electrical nerve stimulation (TENS) on Barthel Activities of Daily Living (ADL) index score following stroke. Clin Rehabil, 1998, 12: 277-280. [Medline] [CrossRef] 